\title{
Predicting future Brent oil price on global markets
}

\author{
MarekVOCHOZKA ${ }^{1}$, JakubHORÁK ${ }^{2}$, Tomáš KRULICKÝY ${ }^{3}$ and Pedro PARDAL ${ }^{4}$
}

Authors' affiliations and addresses:

${ }^{1}$ School of Expertness and Valuation, Institute of Technology and Business, Okruzni 517/10, 37001 Ceske Budejovice, Czech Republic e-mail: vochozka@mail.vstecb.cz

${ }^{2}$ University of Žilina, Faculty of Operation and Economics of Transport and Communications, Univerzitna 8215/1, 01026 Zilina, Slovakia e-mail: horak@mail.vstecb.cz

${ }^{3}$ University of Žilina, Faculty of Operation and Economics of Transport and Communications, Univerzitna 8215/1, 01026 Zilina, Slovakia e-mail: krulicky@mail.vstecb.cz

${ }^{4}$ Polytechnic Institute of Setúbal, Business and Management School, Campus do IPS Estefanilha, 2910-761, Setúbal, Portugal e-mail: pedro.pardal@esce.ips.pt

\section{*Correspondence:}

Marek Vochozka, School of Expertness and Valuation, Institute of Technology and Business, Okruzni 517/10, 37001 Ceske Budejovice, Czech Republic

e-mail: vochozka@mail.vstecb.cz

How to cite this article:

Vochozka, M., Horák, J., Krulický, T. and Pardal, P. (2020). Predicting future Brent oil price on global markets. Acta Montanistica Slovaca, Volume 25 (3), 375-392

DOI:

https://doi.org/10.46544/AMS.v25i3.10

\begin{abstract}
International oil prices affect the development of many areas of the world economy, where most predictions of macroeconomic variables depend on the changes in oil prices. The high volatility of oil prices is a cause of prediction complexity, especially in times of crisis or during the current coronavirus pandemic. In this paper, a special and promising type of artificial neural network - LSTM (Long Short-Term Memory) is used for predicting oil prices. The paper's objective is to predict the development of Brent oil prices' daily values to 30 June 2021. For this purpose, available data for the period from the end of June 1988 to the end of November 2020 was used. To achieve the objective of the paper, two research questions were formulated: whether the created specific neural network is a suitable tool to smooth the time series of Brent oil prices, i.e., a suitable tool to predict the future development of the price of this commodity, and what development of oil price can be expected with regard to the current situation in global markets. It was confirmed that each of the networks retained could smooth the time series successfully, and it can make a reasonable prediction of the future Brent oil price development. This paper's primary finding is that the created neural network with integrated LSTM can be used for predicting Brent oil prices. As for the further development of oil price, the oil market will also respond to the positive development of the economy and the growth of the world economy's overall product, where both the quantity of extracted oil in the market and its price will grow.
\end{abstract}

\section{Keywords}

Artificial neural networks, time series, commodity, prediction of future development, global market, experiment 


\section{Introduction}

Oil or crude oil can be considered natural liquid fossil fuel found in geological formations beneath the Earth's surface. As the most important and indispensable resource, oil has an irreplaceable and important role in the whole economic society. It also plays an essential role in the international market. This important material is used for many chemical industrial products, including pesticides, fertilizers, solvents, etc. Due to the fact it is a non-renewable resource as well as its many derivatives, such as plastics and petrol, oil is an important strategic resource for many countries. As a basic energy product, oil accounts for about $40 \%$ of the global energy consumption.

Oil is currently considered the main output for the production of goods and energy, with its consumption being about 93 million barrels per day. According to Rehman et al. (2018), oil can also be seen as a certain lifebuoy for most industries. Oil production is centralized by the world organization OPEC, whose members control about $73 \%$ of the total production of oil. Ramyar and Kainfar (2019) speak about the necessity and importance of oil and mention entities for which the information about oil prices is particularly important especially enterprises, governments, and policy-makers. The current literature illustrates the importance of global supply and demand for oil and their impact on the real economy since it affects price formation and inflation. It could be said that the vast majority of all predictions of macroeconomic variables depends on the changes in oil prices (Killian, 2009). The fact that the fluctuations of international oil prices affect the development of many areas of the global economy is confirmed in the studies by many researchers (Qiang et al., 2019). Novotný (2012) also states that the oil price changes have various impacts on economies and global markets' financial indicators. Ahmadi et al. (2016) further add that nearly any changes in oil prices may result in changes in the traditional asset markets, such as markets with precious metals. In addition, higher oil prices result in higher energy and production costs, as well as an increase in interest rates. According to Aamir et al. (2018), future oil prices are highly dependent on historical prices. The authors also state that in recent years, the future oil prices are considered very uncertain. For this reason, great attention is currently paid to their prediction, including the methods of measurement, especially from the side of investors, economists, academics, government agencies, etc. (Kliestik, 2018). 2021

The paper's objective is to predict the future development of daily values of Brent oil prices until 30 June

\section{Literature Research}

As the issue of oil prices is relatively complex, it is very difficult to obtain accurate predictions. Machová et al. (2020) state that extreme fluctuations of oil prices significantly influence economic stability, and even the national security, which leads to considerable challenges. For this reason, the creation of a valid model for predicting oil price is considered one of the most efficient solutions to these challenges (Wang et al., 2020). In practice, for predicting oil prices, there have been conducted a number of studies and research as well as models using heuristic approaches, traditional econometric models, or machine learning. Here, we can mention, for example, the research conducted by Baumeister and Kilian (2015), who proposed a method combining 6 different models (including econometric models, such as VAR) of oil price prediction. It shall be noted that many econometric models are linear and thus enable capturing the non-linearity of oil prices. Gao and Lei (2017) proposed a new approach to predicting oil prices based on a new paradigm of machine learning called stream learning. The main advantage of this approach consists of the fact that the model can capture changing patterns in oil prices. To improve the accuracy of the international predictions of oil prices, Chai et al. (2019) created a new hybrid prediction model based on a fuzzy clustering algorithm with dynamic deformation of time. The results of the model show a very good prediction accuracy. Another hybrid model that was tested with ANNs and intended to make more accurate predictions of oil prices was proposed by Tairan et al. (2019). In this case, the results of the simulation were also very good. For predicting oil prices, specifically, WTI (West Texas Intermediate) oil prices, Chiroma et al. (2015) proposed an alternative approach based on genetic algorithm and neural network (GA-NN). In terms of prediction accuracy and computational efficiency, the comparative simulation results indicate that the proposed GA-NN approach shows better accuracy than the basic algorithms. Research conducted by Wang et al. (2011) indicates that the GARCH models are well applicable for capturing long-term WTI oil revenues, while Lin et al. (2020) state that the HM-EGARCH models can identify sudden changes in oil prices.

For predicting oil prices and analysis of the actual oil prices after 1973, Kilian and Lee (2016) used models AR, ARMA, and VAR. It follows from the results that for the period up to 12 months, the prediction accuracy is better than conventional prediction models, but the prediction accuracy of the conventional prediction model is better in the predictions for longer than one year. Qi and Zhang (2009) use Cluster Support Vector Machine for predicting the daily oil price, while Tang et al. (2015) created a newELM model for the same purpose, which is based on CEEMD. On the basis of the empirical results, it can be stated that the model shows a relatively good 
prediction effect. To create a model for predicting oil prices, Wang et al. (2014) reconstruct the run-length method's decomposition sequence. It follows from the prediction results that the accuracy of the prediction model is higher than in the case of the unstructured model.

Studies that use LSTM networks for predicting oil prices can be encountered increasingly often in the scientific world, especially due to their predictive capability. For example, for predicting WTI oil price, Yao and Wang (2020) proposed a method combining the LSTM network and GM model. The study results show that the proposed model has high predictive accuracy, especially in the case of series representing long-term influence with a lower frequency. High accuracy of the models when solving complex classification problems related to oil price prediction was achieved by Hu et al. (2019) using LSTM networks. Cen and Wang (2019) also applied LSTM models for training and predicting the sequence of oil prices, to which different weights were assigned. Wang et al. (2020) add that especially due to the long-term and short-term memory, the LSTM model is capable of simulating sequence autocorrelation and extracting periodic characteristics of the sequence, which has better predictive power than conventional models such as BPNN or ARMA.

\section{Materials and Methods}

Studies that use LSTMIt is obvious that the price of Brent oil influences the performance of the global economy (Vochozka et al., 2020). There has been confirmed the influence the changes in oil prices have on GDP development or even on the exchange rates in individual countries.

Considering the conclusion of the research carried out, the following research questions may be formulated:

RQ1: Is a neural network (in the text also referred to as "NN") based on Long Short Term Memory Layer a suitable tool for smoothing the time series of Brent oil price, and thus a suitable tool for predicting the future development of this commodity price?

RQ2: What development of oil price can be expected in view of the global markets' current situation?

The data for analysis is available from Investing.com (2020). For each trading day of Brent oil, the server offers information about the price, opening price, the highest and the lowest price, volume of trade, and the price change compared to the previous day. For the calculation, only the price of the trade, i.e., the first item in the list, is used. The data is available for the period of 27 June 1988-19 November 2020. The price of oil in the period under review ranges between USD 9.64 per barrel (10 December 1998) and USD 146.08 per barrel (3 July 2008). The average price of Brent oil was USD 48.01 per barrel, while the median was USD 37.05 per barrel. The variance is USD 1064.87; the standard deviation is USD 32.63.

The paper's objective is to predict the future Brent oil prices for the period until 30 June 2021. Considering the data available, it refers to the prediction of the variable for the 157 trading days, which is a very long period. Although Vochozka et al. (2020) proved that technical analysis is not much precise for such a long period, it can still identify the development direction. In such a case, however, it is necessary to work with price as with a path function. An important factor affecting the solving processes of the whole problem is the current emergency situation, where the global economy's performance and the economy of the individual countries are affected by the measures adopted against COVID-19. The further development of the economy will thus be closely related to the spread of COVID-19 and the measures the individual countries will be willing to adopt to prevent this spread. The following part of the text will focus on research questions and the methods that cannot obtain answers.

\section{Research question 1}

The research question assumes the creation of an artificial LSTM neural network or artificial neural networks containing Long Short Term Memory (hereinafter also referred to as "LSTM") Layer. It will also be necessary to determine whether such a $\mathrm{NN}$ is a suitable tool for predicting a business's future value.

The specific structure of the network, especially in terms of data exchange between the individual layers, depends on the experiment results. The experiment's goal is to determine the final form of the neural network's sub-components and determine the amount of data on Brent oil price during the previous days necessary to determine the future (predicted) value. The experiment will be described with the individual components of the neural structure. The individual components are shown in Figure 1.

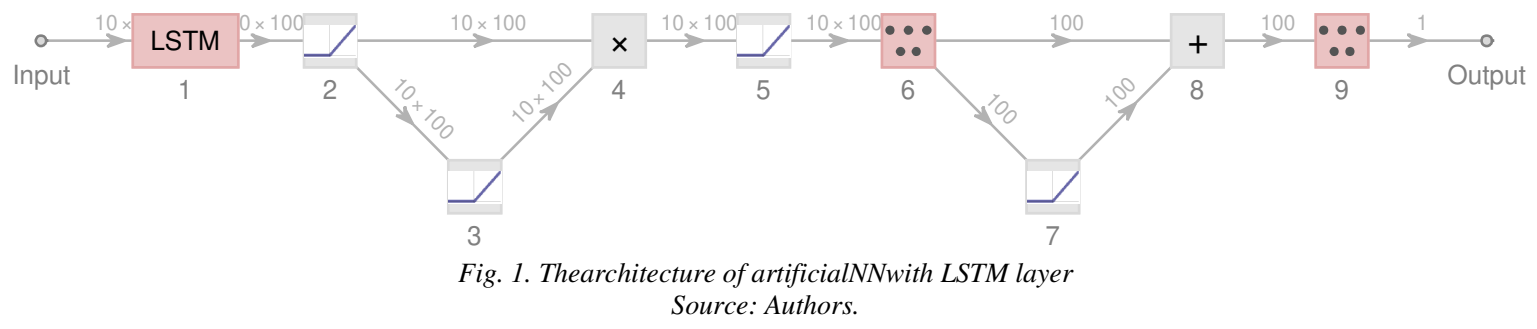


The NN will thus consist of 11 layers, out of which two will represent the input and output layer, and the remaining nine ones can be considered hidden layers:

1. The input layer of neurons: it is a matrix that provides information about the previous prices of Brent oil. Within the experiment, it will be determined what amount of data is the most suitable for their prediction:

a. 10 historical prices - data matrix $1 \times 10$

b. Information about 20 historical prices provides a data matrix $1 \times 20$.

c. 30 historical prices provide a data matrix $1 \times 30$.

2. $1^{\text {st }}$ hidden layer of neurons: the layer consists of the LSTM layer. The output is the matrix $1 \times n$ (for simplification, the matrix in the figure has the form of $10 x 100$, i.e., matrix at the output of the layer $10 \times 100^{1}$ ). Determining the number of elements in the matrix at the output will be a part of the experiment. The size of the matrix affects the predictive capability of the model; the excessively low number of matrix elements may cause a higher inaccuracy of the result, while a high number of elements may result in excessive complexity and overfitting of the model, which will show excellent trained NN parameters in smoothing time series but a nonsensical prediction of its further development. The number of elements will be determined at the interval of 10-4000 elements with 10 steps.

3. $2^{\text {nd }}$ hidden layer: it is an Element-wise layer (a simple network working with perceptron). Its task is to bring a certain degree of non-linearity in the NN. Even in this case, a sub-experiment will be carried out to test the suitability of functions transmitting the signal. Functions for this layer are selected randomly:

a. Hyperbolic tangent (Tanh):

$$
f(x)=\tanh x=\frac{e^{x}-e^{-x}}{e^{x}+e^{-x}}
$$

where $f(x)$ is a function value of independent variable, $\tan (x)$ is hyperbolic tangent, $e^{+-x}$ is natural exponential function.

b. Sinus $(\operatorname{Sin})$ :

$$
f(x)=\sin x
$$

where $f(x)$ is a function value of an independent variable.

c. Ramp (sometimes also ReLU):

$$
R(x): R \rightarrow R_{0}^{+}
$$

where $R(x)$ is a function value of an independent variable, $R$ gives $x$ if $x \geq 0$ and 0 otherwise.

d. Logistic function (Logistic Sigmoid):

$$
f(x)=\frac{1}{1+e^{-x}}
$$

where $f(x)$ is a function value of independent variable, $e^{-x}$ is natural exponential function.

4. $3^{\text {rd }}$ hidden layer: it is an Element-wise layer. Its further setting corresponds to the $2^{\text {nd }}$ hidden layer (i.e., the specific function for transmitting the signal will be selected randomly).

5. $4^{\text {th }}$ hidden layer of neurons: it is a Times layer. Its task is to mutually multiply the signals of the $2^{\text {nd }}$ and $3^{\text {rd }}$ layer, unify the signal and transmit it.

6. $5^{\text {th }}$ hidden layer of neurons: it is an Element-wise Layer. Its further setting corresponds to the $2^{\text {nd }}$ hidden layer (i.e., the specific function for transmitting the signal will be selected randomly).

7. $6^{\text {th }}$ hidden layer of neurons: this layer is formed by the Linear Layer. At its input, there is a data matrix, while at its output, there is a vector with $n$ elements. The number of vector elements equals the number of LSTM Layer matrix in the $1^{\text {st }}$ hidden layer. The scheme in Figure 1 shows 100 vector elements.

8. $7^{\text {th }}$ hidden layer of neurons: it represents the last Element-wise Layer. Its further setting corresponds to the $2^{\text {nd }}$ hidden layer (i.e., the specific function for transmitting the signal will be selected randomly).

\footnotetext{
${ }^{I}$ It should be rather seen as 10 vectors with 100 elements.
} 
9. $8^{\text {th }}$ hidden layer: the Plus layer is determined. Its task is to connect (add) the signals of the $6^{\text {th }}$ and $7^{\text {th }}$ hidden layer and transmit them.

10. $9^{\text {th }}$ hidden layer of neurons: this layer is formed by the Linear Layer. At its input, there is a vector with $n$ elements (the vector in Figure 1 has 100 elements); at the input, there is a vector with 1 element.

11. Output layer: Brent oil price will be predicted.

\section{Long-Short Term Memory Layer}

The methodology presents the entire architecture of the artificial neural structure. However, the LSTM Layer is a very specific NN. It is a recurrent NN.

The LSTM Layer assumes four basic processes represented by input gate, output gate, forget gate, and a memory gate. The state of the cell is defined as follows:

$$
c_{t}=f_{t} * c_{t-1}+i_{t} * m_{t}
$$

where $c_{t}$ is a new state of the variable, $f_{t}$ forget gate, $c_{t-1}$ initial state of the variable, $i_{t}$ input gate, $m_{t}$ memory gate.

Where input gate is defined as follows:

$i_{t}=\sigma\left[W_{i x} x_{t}+W_{i s} s_{t-1}+b_{i}\right]$

where $\sigma$ is Logistic Sigmoid, $W_{i x}$ input weight in input gate, matrix $n x k, x_{t}$ input variable, matrix $n x k, W_{i s}$ the weight of the state in input gate, matrix $n \times n, s_{t-1}$ previous state, $b_{i}$ bias, vector of $n$ size

The state is given by the following equation:

$s_{t}=o_{t} * \operatorname{Tanh}\left[c_{t}\right]$

where $s_{t}$ is a state of the variable, $o_{t}$ output gate,Tanhhyperbolic tangent.

Output gate is expressed by the following equation:

$o_{t}=\sigma\left[W_{a x} x_{t}+W_{a s} s_{t-1}+b_{o}\right]$

where $W_{a x}$ is the input weight in output gate, matrix $n x k, W_{a s}$ the weight of the state in output gate, matrix $n x$ $n, b_{o}$ bias, vector of $n$ size.

An important innovation of LSTM is the forget gate:

$$
f_{t}=\sigma\left[W_{f x} x_{t}+W_{f s} s_{t-1}+b_{f}\right]
$$

where $W_{f x}$ determines the input weights in forget gate, matrix $x k, W_{f s}$ weight of the state in forget gate, matrix $n \times n, b$ bias, vector of $n$ size

The remaining main process to be determined is the memory gate:

$$
m_{t}=\operatorname{Tanh}\left[W_{m x} x_{t}+W_{m s} s_{t-1}+b_{m}\right]
$$

where $W_{m x}$ is the input weight in memory gate, matrix $n x k, W_{m s}$ weight of the state in memory gate, matrix $n$ $x n, B_{m}$ bias, vector of $n$ size

For the volumes of data containing 10, 20, and 30 pieces of information about the previous oil price, 400 $\mathrm{NN}$ will be created for each volume. NN will be trained using the ADAM algorithm (method of stochastic optimization, Adaptive Moment Estimation - Kingma and Ba, 2015). For each volume of data, five NN with the best performance will be selected. The performance will be measured using the Pearson correlation coefficient of smoothed time series and the actual development of Brent oil prices in the period of 27 June 1988-19 November 2020. Subsequently, the future development of Brent oil price will be developed using the retained NN. There will thus be 15 predictions for the period until 30 June 2021 available.

The answer to Research Question 1 will be obtained using the value of the correlation coefficients of the smoothed time series and the actual development of oil prices in the monitored period. If there is dependence, or strong dependence, identified (the value of Pearson correlation coefficient is over 0.7), it can be confirmed that NN with the LSTM Layer is suitable for predicting the future development of Brent oil prices. Given that NN generally show higher accuracy than the traditional statistic methods, the limit of the Pearson correlation coefficient for making a positive conclusion is determined at 0.95 . 


\section{Research Question 2}

As mentioned above, the global economic situation is complicated nowadays, especially due to the measures adopted against the spread of COVID-19. The economic performance decreases in a number of industries, and individual countries are in debt. Thus, it is logical that in this extraordinary period, the authors will have to work with various scenarios. Thus, there will be predicted the development of Brent oil prices in the period of global economic growth, stagnation, and decline.

The answer to Research Question 2 will thus be the development of Brent oil prices in dependence on the global economy's development.

\section{Results}

As already mentioned in the methodology part, a total of 15 artificial $\mathrm{NN}$ were retained -5 for each 10,20 , and 30 input data on the previous oil price.

\section{NN with 10-day time delay}

Table 1 presents the structure of the retained $\mathrm{NN}$ and their performance in the form of the Pearson correlation coefficient.

\begin{tabular}{clc} 
& \multicolumn{2}{c}{ Tab.1. Structure of retained NN for 10 input data on Brent oil price and network performance } \\
\hline ID NN & \multicolumn{1}{c}{ NN } & Training performance \\
\hline 1NN10 & 10-210-Sin-Ramp-Sin-210-Logistic-1 & 0.999252 \\
2NN10 & 10-340-Sin-Logistic-Ramp-340-Tanh-1 & 0.999254 \\
3NN10 & 10-180-Sin-Logistic-Tanh-180-Sin-1 & 0.999266 \\
4NN10 & 10-370-Tanh-Logistic-Ramp-370-Ramp-1 & 0.999283 \\
5NN10 & 10-290-Sin-Logistic-Tanh-290-Ramp-1 & 0.999348 \\
\hline
\end{tabular}

Source: Authors.

The first column of the table contains the identification number to the NN; the second column represents the NN structure. The third column shows the performance of each NN

As for the structure, the first number represents the number of the input data (matrix $1 \times 10$ ). The second element, a digit, represents the size of the matrix, which is the LSTM layer's output (in the case of 1NN10, it is matrix $10 \times 210$ ). The next three positions are the information about the functions that propagate the signal in the $2^{\text {nd }}, 3^{\text {rd }}$, and $5^{\text {th }}$ hidden layer. Then there is information about the vector's size based on the Linear Layer, i.e., the $6^{\text {th }}$ hidden layer. This is followed by the information about the function propagating the signal in the neural structure ( $7^{\text {th }}$ hidden layer Element-wise Layer). The last element of the structure provides information about the vector's size based on the $9^{\text {th }}$ hidden layer (Linear Layer). Information about the performance of the individual networks' performance is also very important. The Pearson correlation coefficient is higher than 0.999 in the case of all five networks. The best performance is recorded in the case of the 5NN10 network. Figure 2 shows how the networks $1 \mathrm{NN} 10-5 \mathrm{NN} 10$ were able to smooth the time series under review.

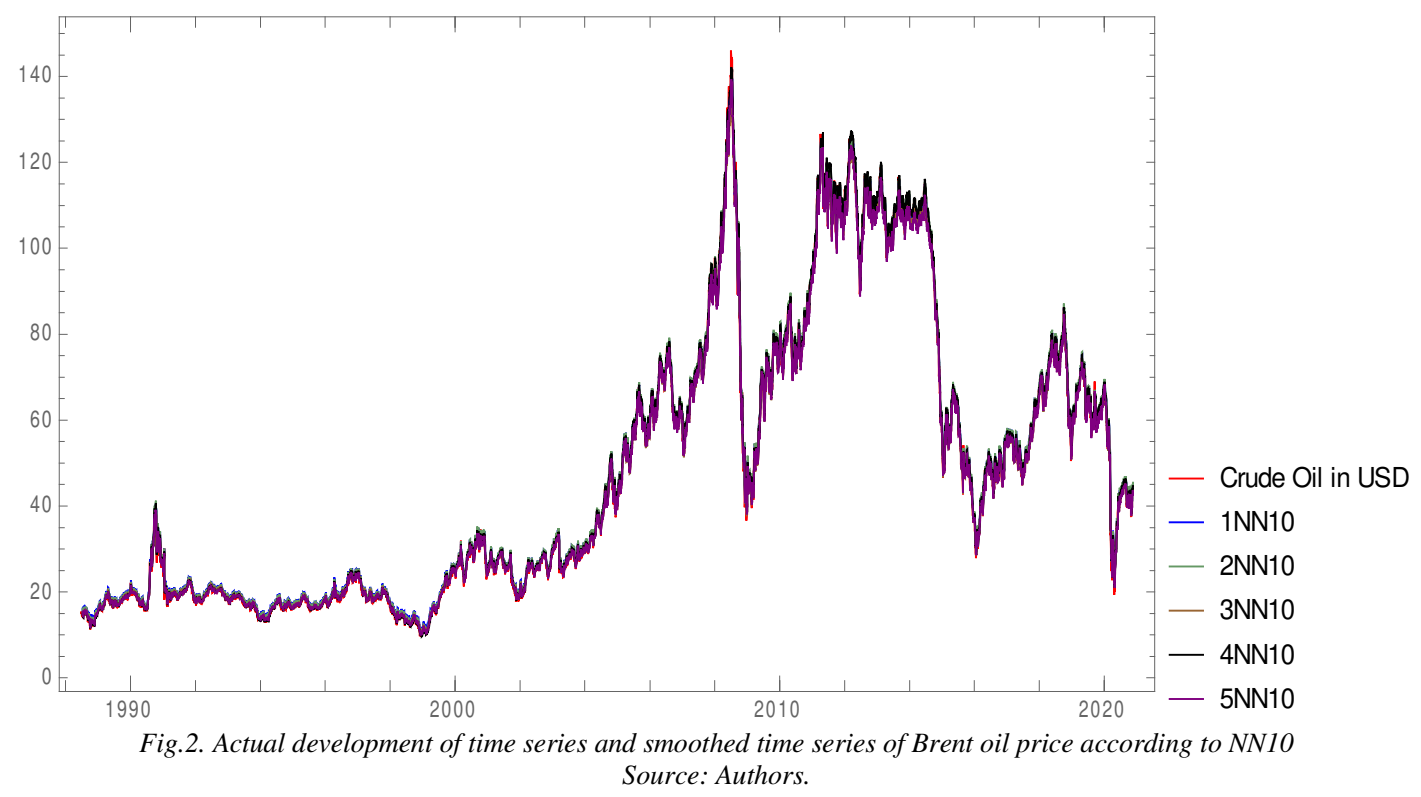


It follows from the figure above that all retained $\mathrm{NN}$ are able to smooth the time series under review. They are able to successfully smooth both global and local extremes of the time series. The parameters of the time series and smoothed time series are presented in Table 2.

Tab. 2. Parameters of timeseries and smoothedtimeseriesaccording to NN1O

\begin{tabular}{l|lllll} 
& Minimum & Maximum & Mean & Standard Deviation & Variance \\
\hline Crude 0il in USD & 9.64 & 146.08 & 48.0146 & 32.6343 & 1065. \\
1NN10 & 10.96 & 140.27 & 48.8765 & 32.3619 & 1047.29 \\
2NN10 & 10.56 & 137.28 & 49.0676 & 32.6762 & 1067.73 \\
3NN10 & 10.23 & 134.89 & 47.8132 & 32.0331 & 1026.12 \\
4NN10 & 9.68 & 142.14 & 48.5735 & 33.0165 & 1090.09 \\
5NN10 & 9.99 & 139.38 & 47.5609 & 31.8801 & 1016.34 \\
& \multicolumn{5}{c}{ Source: Authors. }
\end{tabular}

Figure 3 shows predictions of future development of Brent oil prices for the period from 20 November 2020 to 30 June 2021.

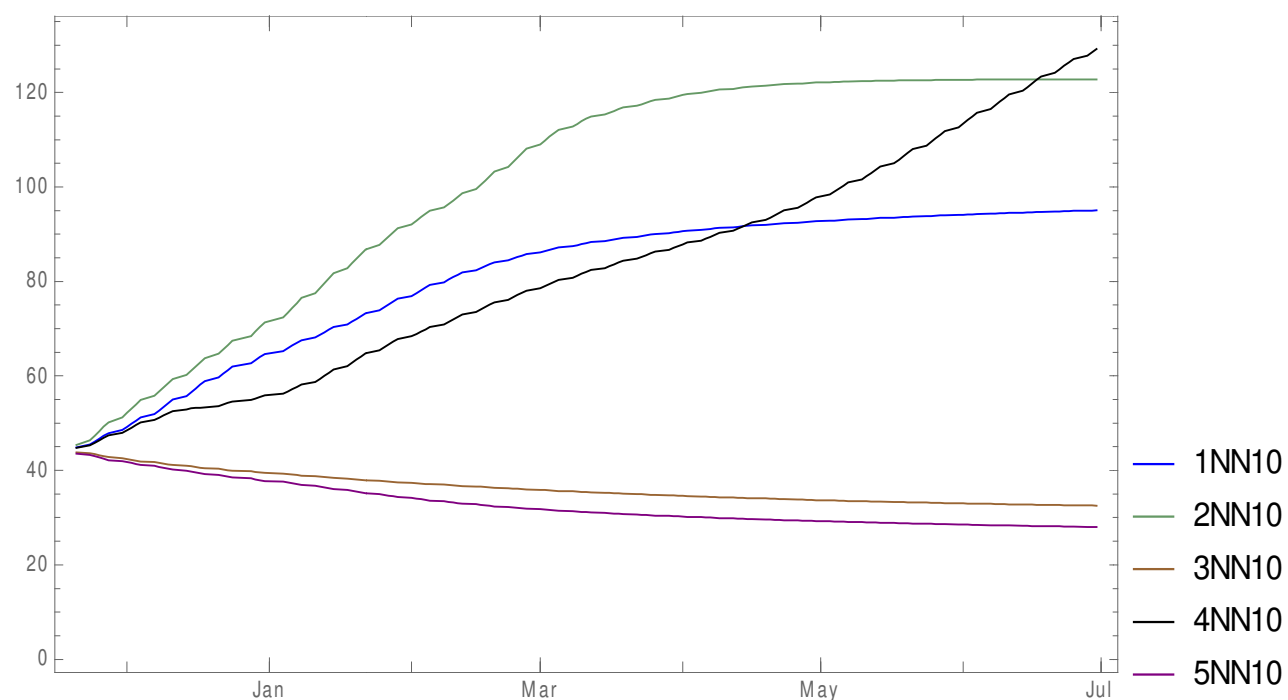

Fig.3. Prediction of Brent oil price development between 20 November 2020 and 30 June 2021 according to NN10 Source: Authors.

Although the networks 1NN10 - 5NN10 smoothed the time series with the performance with a value higher than 0.999 , their development predictions differ significantly. 4NN10 predicts a stable and fast growth. NN $1 \mathrm{NN} 10$ and 2NN10 predict very rapid growth of Brent oil prices and subsequently nearly stabilization at the level achieved. NN 3NN10 and 5NN10 predict a slow, gradual decline to the level slightly above the initial price as of 19 November 2020. The parameters of the time series of the predicted development are shown in Table 3 .

\begin{tabular}{l|lllll}
\multicolumn{7}{c}{ Tab. 3. Parameters of predictingBrentoilpricesaccording to NN10 } \\
& Minimum & Maximum & Mean & Standard Deviation & Variance \\
\hline 1NN10 & 44.88 & 95.05 & 81.0901 & 15.0328 & 225.984 \\
2NN10 & 45.39 & 122.81 & 101.351 & 24.8684 & 618.439 \\
3NN10 & 32.54 & 43.79 & 36.2014 & 3.09637 & 9.58754 \\
4NN10 & 44.81 & 129.22 & 82.8931 & 23.631 & 558.423 \\
5NN10 & 28.01 & 43.57 & 32.7688 & 4.43898 & 19.7046
\end{tabular}

\section{NN with a 20-day time delay}

The retained NN working with twenty pieces of data concerning the previous Brent oil prices are presented in Table 4.

Tab. 4. Structure of retainedNNfor 20 pieces of inputdata on Brentoilprice, includingnetworkperformance

\begin{tabular}{llc} 
& \multicolumn{1}{c}{ NN } & Training performance \\
\hline ID NN & \multicolumn{1}{c}{ No-230-Tanh-Logistic-Tanh-230-Tanh-1 } & 0.999149 \\
1NN20 & 20-170- Tanh-Logistic-Tanh-170-Ramp-1 & 0.999171 \\
2NN20 & 20-130-Ramp-Logistic-Tanh-130-Sin-1 & 0.999201 \\
3NN20 & 20-120-Sin-Ramp-Sin-120-Sin-1 & 0.999206 \\
4NN20 & 20-290-Tanh-Sin-Sin-290-Sin-1 & 0.999224 \\
5NN20 & Source: Authors. \\
\hline
\end{tabular}


In this case, the networks show very high performance. The value of the Pearson correlation coefficient of all networks is higher than 0.999. The ability to smooth the time series under review is shown in Figure 4.

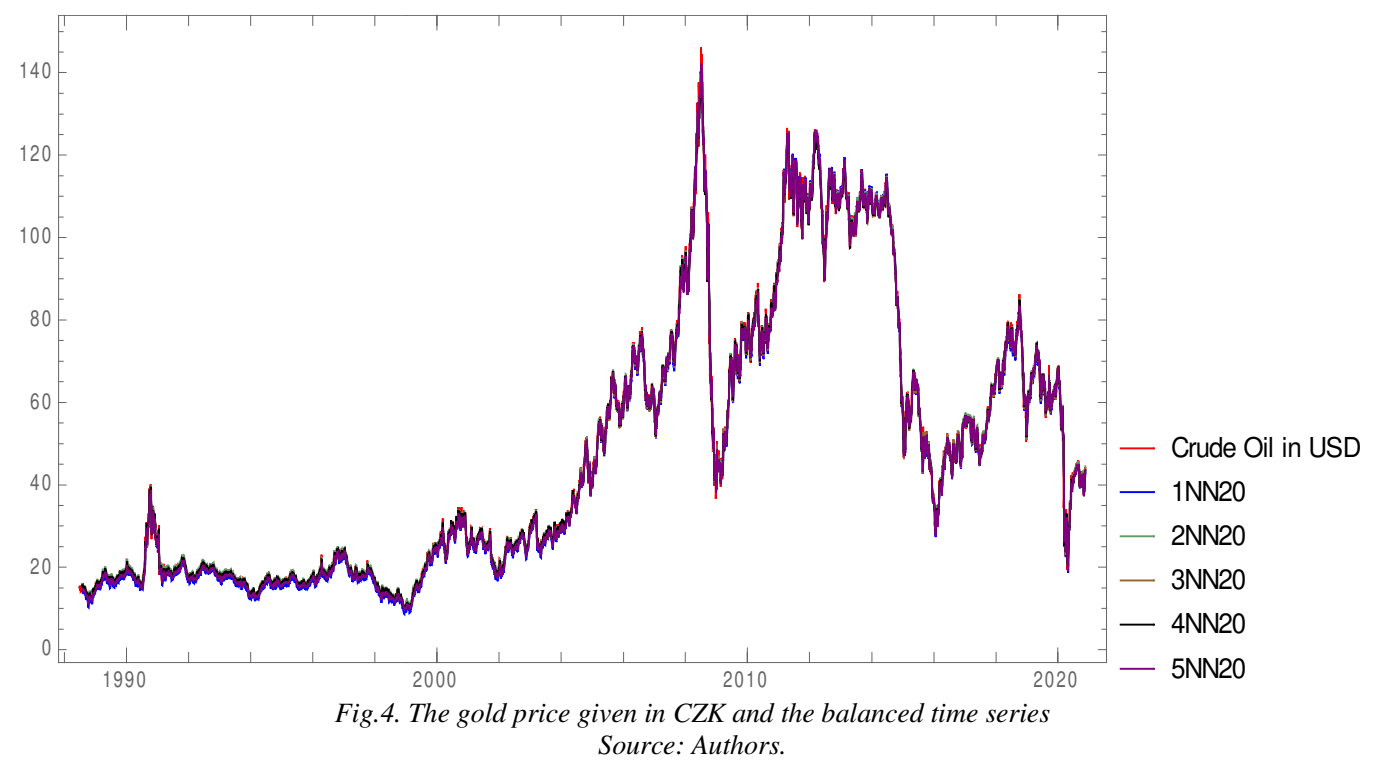

The figure clearly shows that all the retained networks NN20 can smooth the time series under review and its global and local extremes. The characteristics of the Bren oil price time series and smoothed time series are presented in Table 5.

\begin{tabular}{l|lllll}
\multicolumn{6}{c}{ Tab. 5. Parameters of timeseries and smoothedtimeseriesaccording to NN20 } \\
& Minimum & Maximum & Mean & Standard Deviation & Variance \\
\hline Crude 0il in USD & 9.64 & 146.08 & 48.0146 & 32.6343 & 1065. \\
1NN20 & 8.64 & 134.86 & 47.1971 & 33.0307 & 1091.03 \\
2NN20 & 10.02 & 138.26 & 48.4128 & 32.5862 & 1061.86 \\
3NN20 & 10.18 & 136.38 & 47.5741 & 32.327 & 1045.04 \\
4NN20 & 10.05 & 138.21 & 47.8487 & 32.3175 & 1044.42 \\
5NN20 & 9.8 & 142.18 & 47.5626 & 32.7558 & 1072.94
\end{tabular}

Source: Authors.

Prediction of future development according to NN20 is represented graphically in Figure 6.

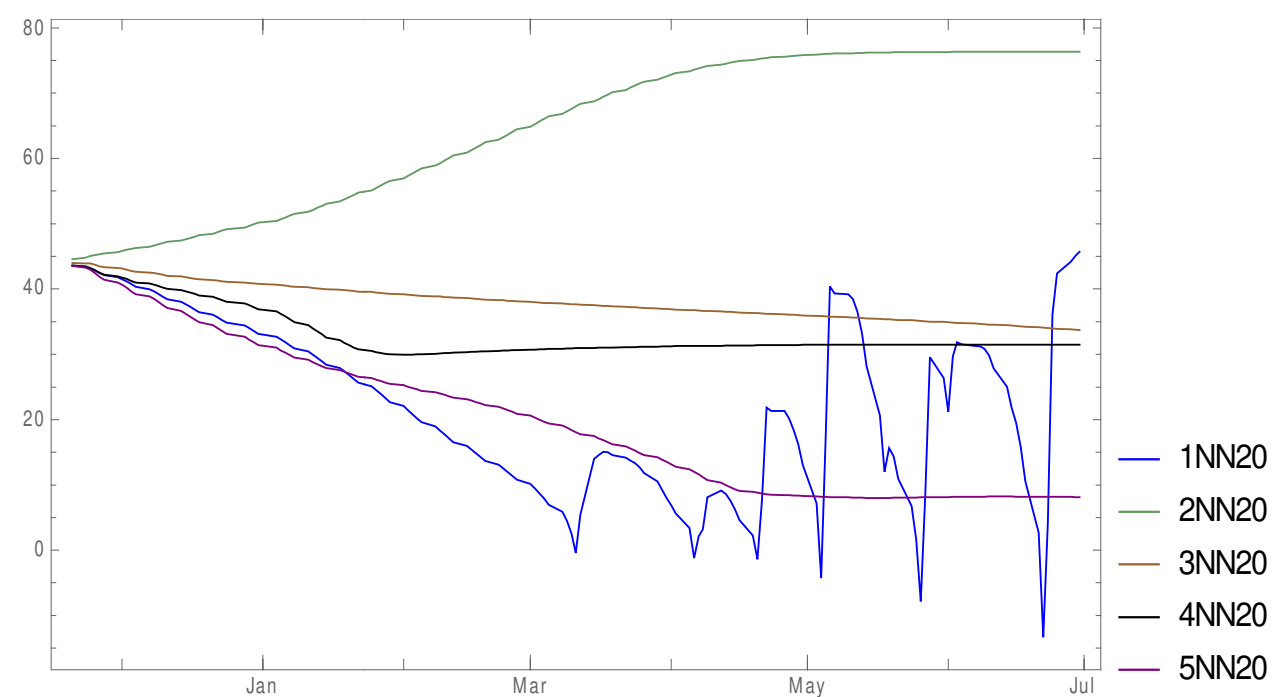

Fig.5. Prediction of Brent oil price development for the period of 20 November to 30 June 2021 according to NN2O Source: Authors. 
It follows from the figure that $5 \mathrm{NN} 20$ predicts a significant price fall and its subsequent stagnation between USD 5 and 10 per barrel. 3NN20 and 4NN20 predict a slow, gradual price fall to USD 30-35 as of 30 June 2021. 2NN20 predicts rapid growth of oil price and its stagnation approx. at USD 75-80 per barrel in April. A very interesting yet unlikely prediction is made by $1 \mathrm{NN} 20$, predicting a rapid price fall and subsequent large fluctuations achieving even negative values. Although such situations have occurred, such a development is not probable. Table 6 presents the statistical characteristics of the predictions.

\begin{tabular}{l|lllll}
\multicolumn{7}{c}{ Tab. 6. Parameters of predictedprices of Brentoilaccording to NN20 } \\
& Minimum & Maximum & Mean & Standard Deviation & Variance \\
\hline 1NN20 & -13.33 & 45.71 & 21.7947 & 13.4398 & 180.628 \\
2NN20 & 44.54 & 76.32 & 64.6933 & 11.4813 & 131.821 \\
3NN20 & 33.73 & 43.96 & 37.9685 & 2.71221 & 7.35607 \\
4NN20 & 29.95 & 43.62 & 33.0243 & 3.70291 & 13.7115 \\
5NN20 & 8.02 & 43.53 & 19.5673 & 11.1762 & 124.907 \\
& & \multicolumn{5}{c}{ Source: Authors. }
\end{tabular}

\section{NN with a 30-day time delay}

The last part of the experiment's output are retained NN, which use 30 pieces of previous data on Brent oil prices for calculating the predictions (Table 7).

Tab. 7. Structure of retained NN for 30 pieces of input data on Brent oil prices, including network performance

\begin{tabular}{llc}
\hline ID NN & \multicolumn{1}{c}{ NN } & Training performance \\
\hline 1NN30 & 10-210-Sin-Ramp-Sin-210-Logistic-1 & 0.999101 \\
2NN30 & 14-340-Sin-Logistic-Ramp-340-Tanh-1 & 0.999106 \\
3NN30 & 14-180-Sin-Logistic-Tanh-180-Sin-1 & 0.999115 \\
4NN30 & 14-370-Tanh-Logistic-Ramp-370-Ramp-1 & 0.999129 \\
5NN30 & 10-290-Sin-Logistic-Tanh-290-Ramp-1 & 0.999152 \\
\hline
\end{tabular}

Source: Authors.

Even in this case, the performance of all NN30 achieves values higher than 0.999. Although the performance of NN30 is worse than in the case of NN10 and NN20, the difference is negligible. Figure 6 shows the ability of NN30 to smooth the time series under review.

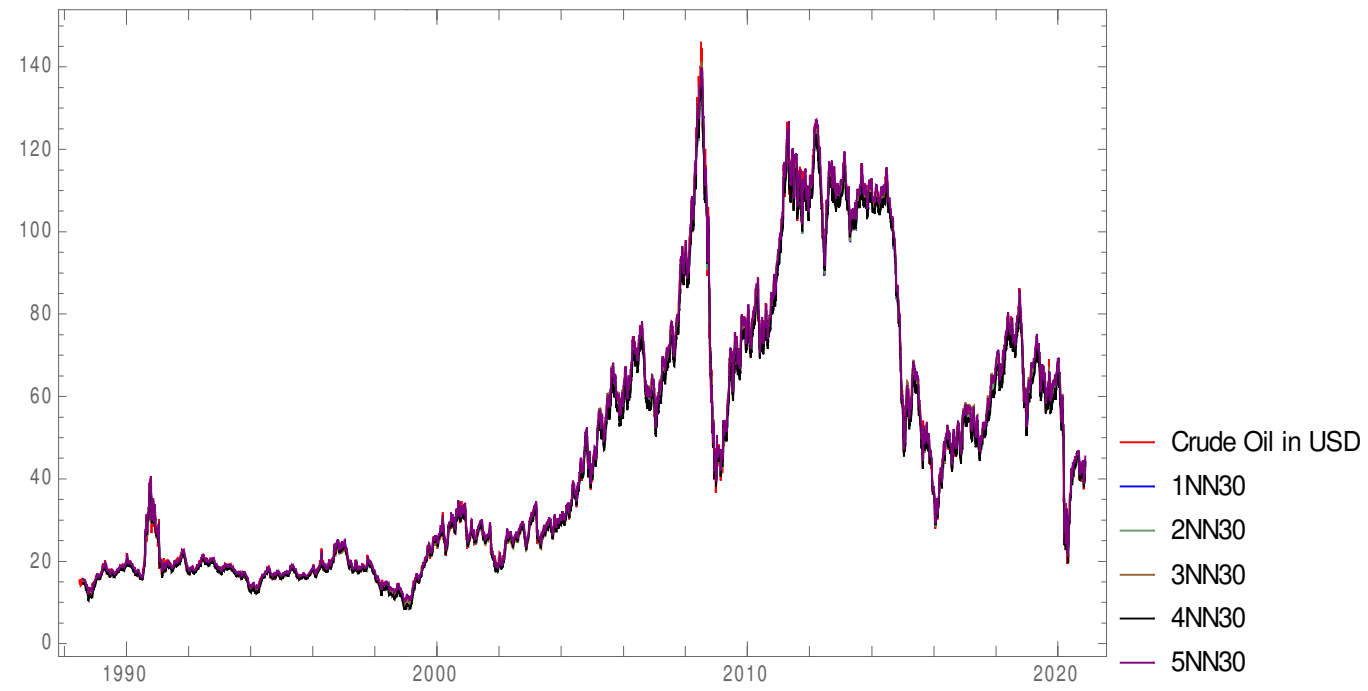

Fig.6. The actual development of time series and smoothed time series of Brent oil price according to NN30 Source: Authors.

Even in the case of NN30, all the retained networks can successfully smooth the Brent oil price time series and are also able to smooth the global and local extremes of the time series. The characteristics of the time series under review and the smoothed time series according to NN30 are shown in Table 8. 


\begin{tabular}{l|lllll}
\multicolumn{5}{c}{ Tab. 8. Parameters of timeseries and smoothedtimeseriesaccording to NN30 } \\
& Minimum & Maximum & Mean & Standard Deviation & Variance \\
\hline Crude 0il in USD & 9.64 & 146.08 & 48.0146 & 32.6343 & 1065. \\
1NN30 & 9.69 & 136.48 & 47.6954 & 32.0591 & 1027.78 \\
2NN30 & 9.08 & 134.69 & 47.4072 & 31.9947 & 1023.66 \\
3NN30 & 9.66 & 141.25 & 48.1347 & 32.6876 & 1068.48 \\
4NN30 & 8.31 & 139.18 & 47.0201 & 31.9362 & 1019.92 \\
5NN30 & 10.33 & 139.82 & 48.8234 & 32.8606 & 1079.82 \\
& \multicolumn{5}{c}{ Source: Authors. }
\end{tabular}

NN30 were also used to predict the future development of Brent oil price until 30 June 2020 (Figure 7).

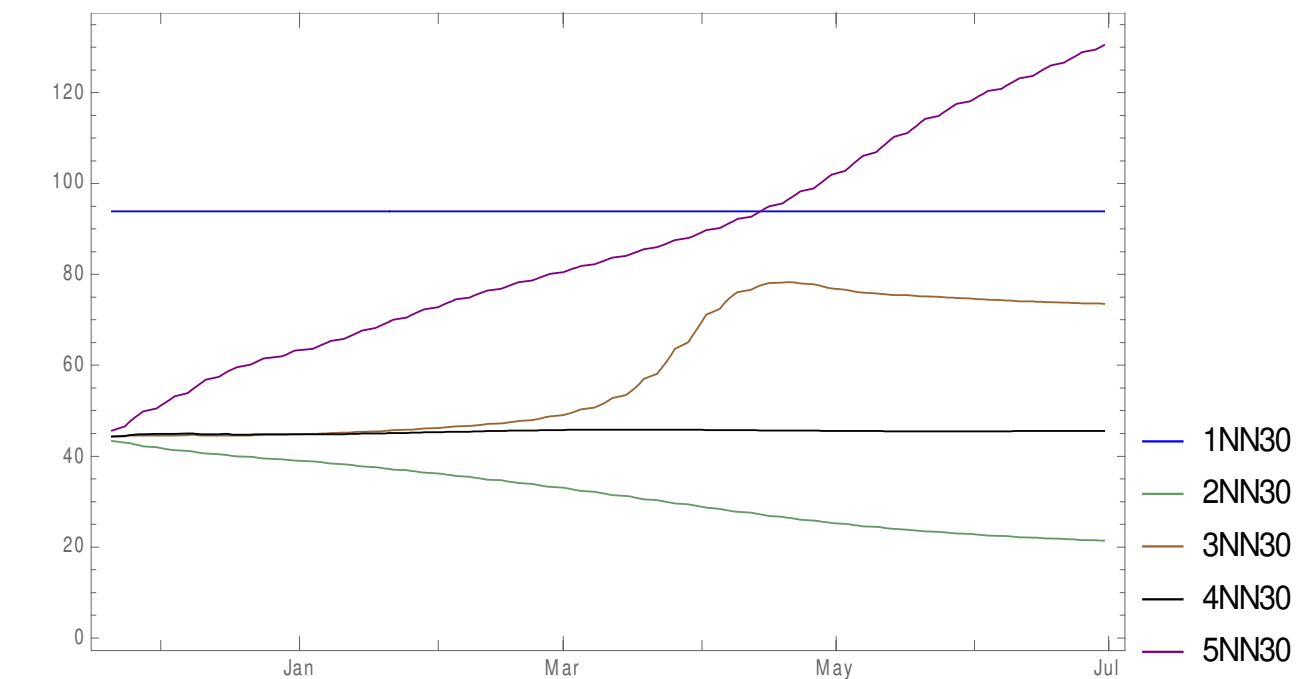

Fig.7. Predicted development of Brent oil prices for the period of 20 November 2020 - 30 June 2021 according to NN30 Source: Authors.

The graph shows that $2 \mathrm{NN} 30$ predicts a slow, gradual price fall at the end of the monitored period (to USD 20 per barrel). $1 \mathrm{NN} 30$ and $4 \mathrm{NN} 30$ predict a stable price (approx. USD 45 , or 95 per barrel). $3 \mathrm{NN} 30$ predict a stable price (approx. USD 45 per barrel) followed by the rapid growth of the price to nearly USD 80 per barrel and a subsequent slow decline to less than USD 75 per barrel. 5NN30 predict an increase of up to USD 130 at the end of the monitored period. The characteristics of the predictions are presented in Table 9.

\begin{tabular}{c|lllll}
\multicolumn{6}{c}{ Tab. 9. Parameters of timeseries and smoothedtimeseriesaccording to NN30 } \\
& Minimum & Maximum & Mean & Standard Deviation & Variance \\
\hline INN30 & 93.92 & 93.92 & 93.92 & 0. & 0. \\
2NN30 & 21.41 & 43.32 & 31.4069 & 6.83847 & 46.7646 \\
3NN30 & 44.26 & 78.28 & 59.4011 & 14.0618 & 197.735 \\
4NN30 & 44.32 & 45.86 & 45.3989 & 0.373873 & 0.139781 \\
5NN30 & 45.67 & 130.47 & 86.658 & 23.348 & 545.13 \\
& & & Source: Authors.
\end{tabular}

\section{Prediction of future development of oil prices until 30 June 2021}

As seen from the paper's research and methodology, it is currently not possible to predict the future development of the economy, and thus determining the possible development of Brent oil prices in the world market unambiguously is not possible, either. However, it is possible to work with some scenarios.

\section{Scenario 1}

We assume that the performance of the global economy (and thus its overall product) will decline. For predicting such a development, $4 \mathrm{NN} 20$ is selected. The graphical representation of the NN is shown in Figure 8 . 


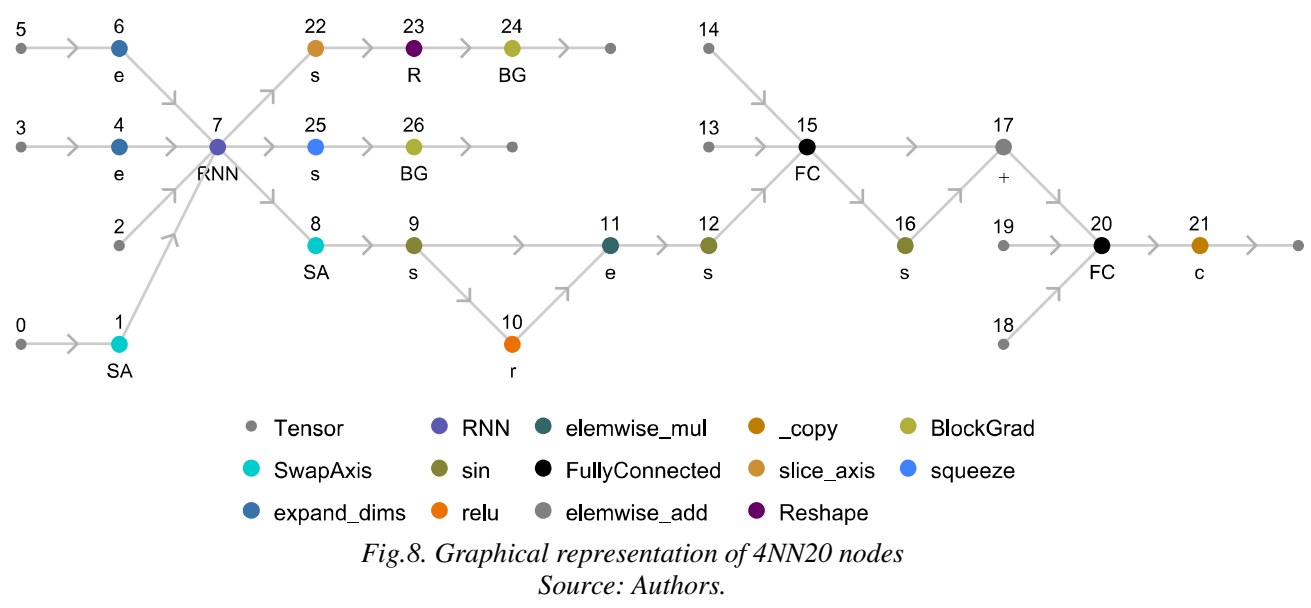

Figure 9 shows the ability of the 4NN20 to smooth the Brent oil price time series in the left part. In the right part, the figure presents the residuals expressed as USD per barrel.

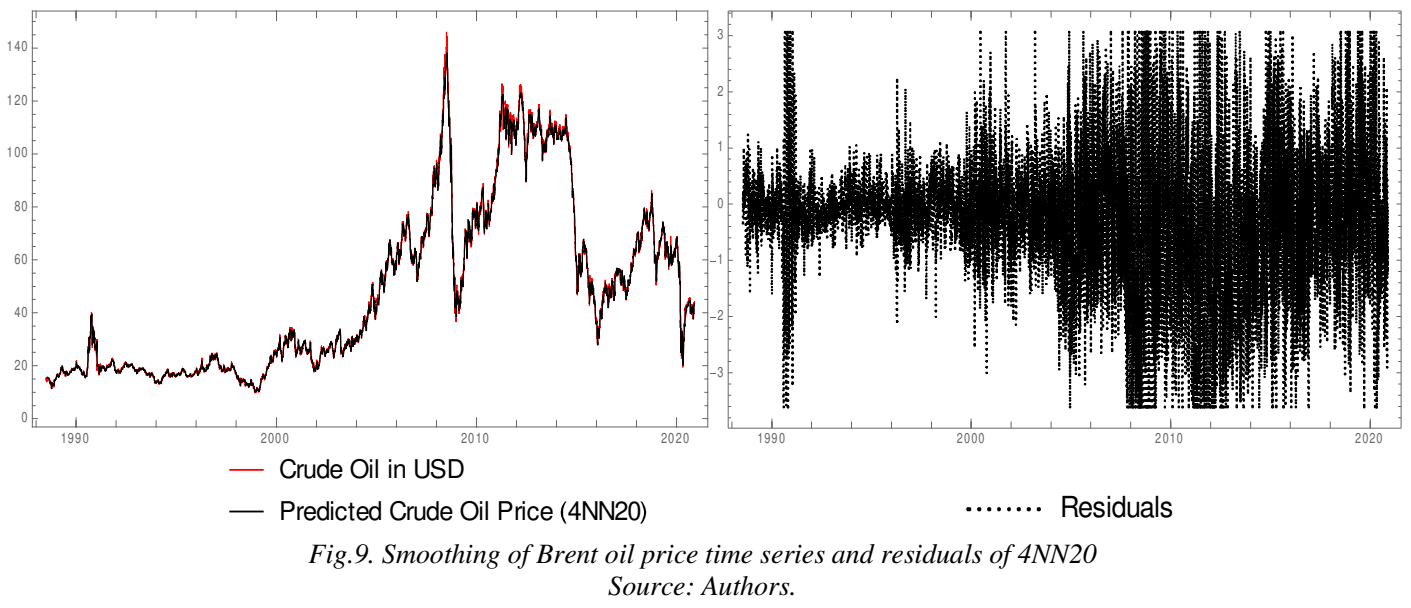

As mentioned above, 4NN20 successfully smooths the time series under review. The prediction itself can be seen in Figure 10.

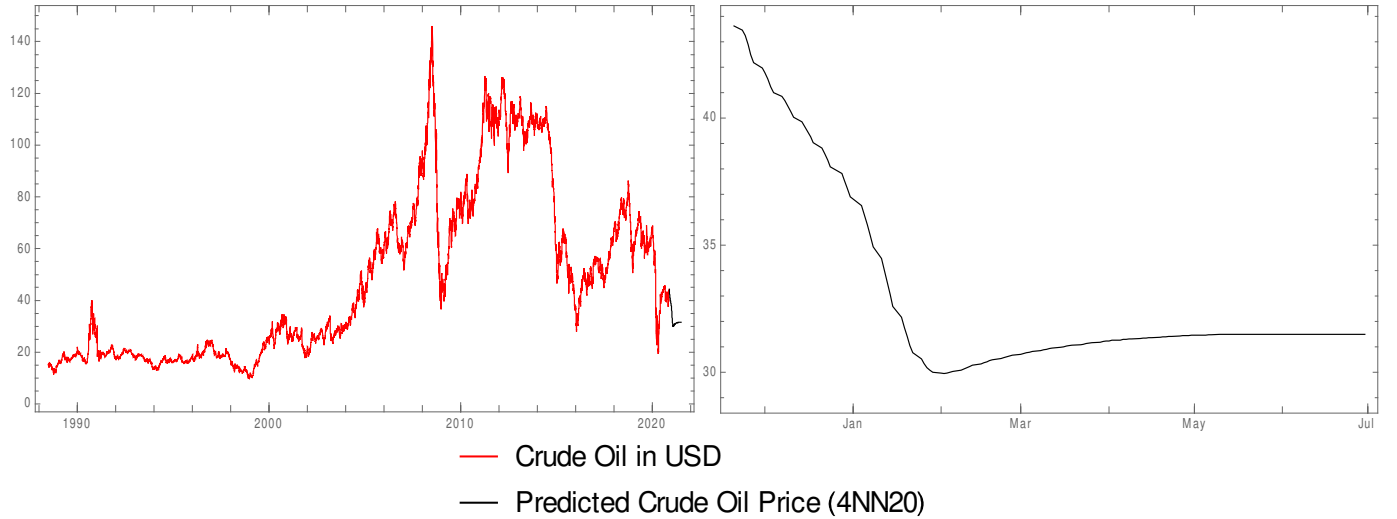

Fig.10. Prediction of Brentoilpriceaccording to 4 NN20 in thecontext of itsdevelopment to date, and the detail of pricedevelopment in a givenperiod

Source: Authors.

The figure clearly shows the relatively rapid decline of Brent oil. This is given by the response to the development of the global economy, which will be affected by the measures adopted against the spread of COVID-19. Individual countries hoping for an early end of the coronavirus pandemic increase their spending despite decreasing GDP. This opens a gap between budget revenues and expenditures, with growing expenditures. Governments want to ease their citizens' concerns and make them believe in the pandemic's early and optimistic ending. They, therefore, borrow funds to finance their expenditures, and the performance of the economy decreases. This results (even with regard to the limited possibility to travel) in the decrease in the 
demand for oil. As many countries are dependent on oil production, they reduce the price of oil to maintain their position in the market and not lose all their income. The price of oil is thus expected to decrease below USD 30 per barrel. This will be followed by a slight increase, achieving USD 32-33 per barrel in June. In the past, cartels intervened in such cases; the problem was that cartel members' morale was not firm, and the countries often did not comply with the agreements concerning the oil extraction limits.

\section{Scenario 2}

The second scenario assumes a relatively positive development of the global economy. More precisely, it assumes that the governments of individual countries will be in debt; however, the debt will not be so large that it would significantly reduce the national economic performance. The scenario assumes the stagnation of the global economic performance, which will be followed by a growth in the demand and consumption due to the positive information about the decline in the coronavirus pandemic, and finally, a growth of the global economic performance. Due to its speed, the period of sharp growth will be relatively short, and the global economy's performance will stabilize at a new level, which will slightly decrease after the enthusiasm subsides.

Such a development corresponds to the prediction according to 3NN30. The network diagram is presented in Figure 11.

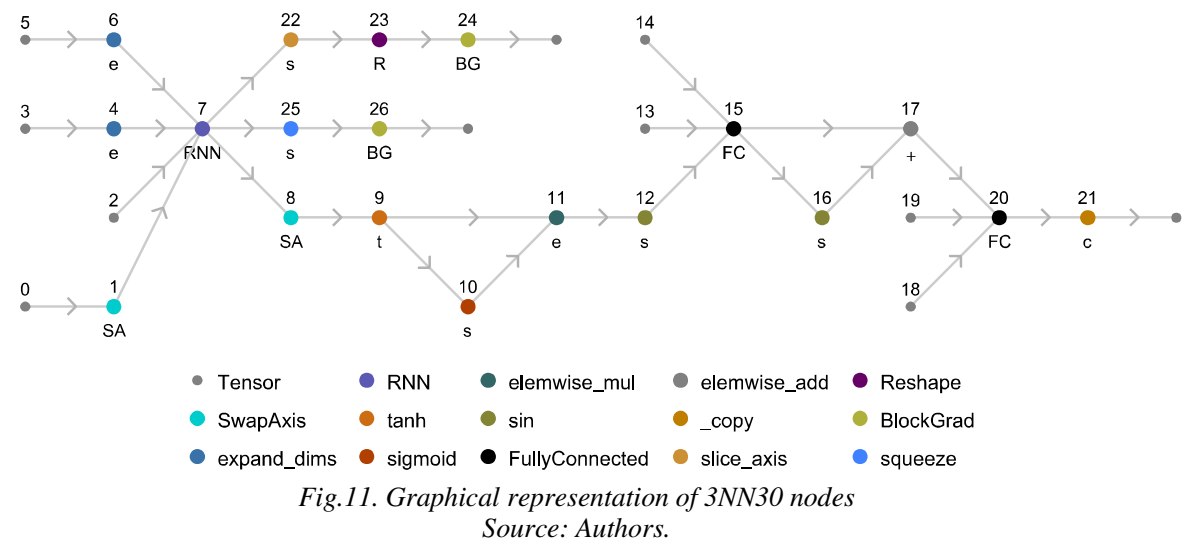

In its left part, Figure 12 shows the ability of 3NN30 to smooth Brent oil price time series in the period until 19 November 2020. The right part of the figure shows residuals expressed in USD per barrel.

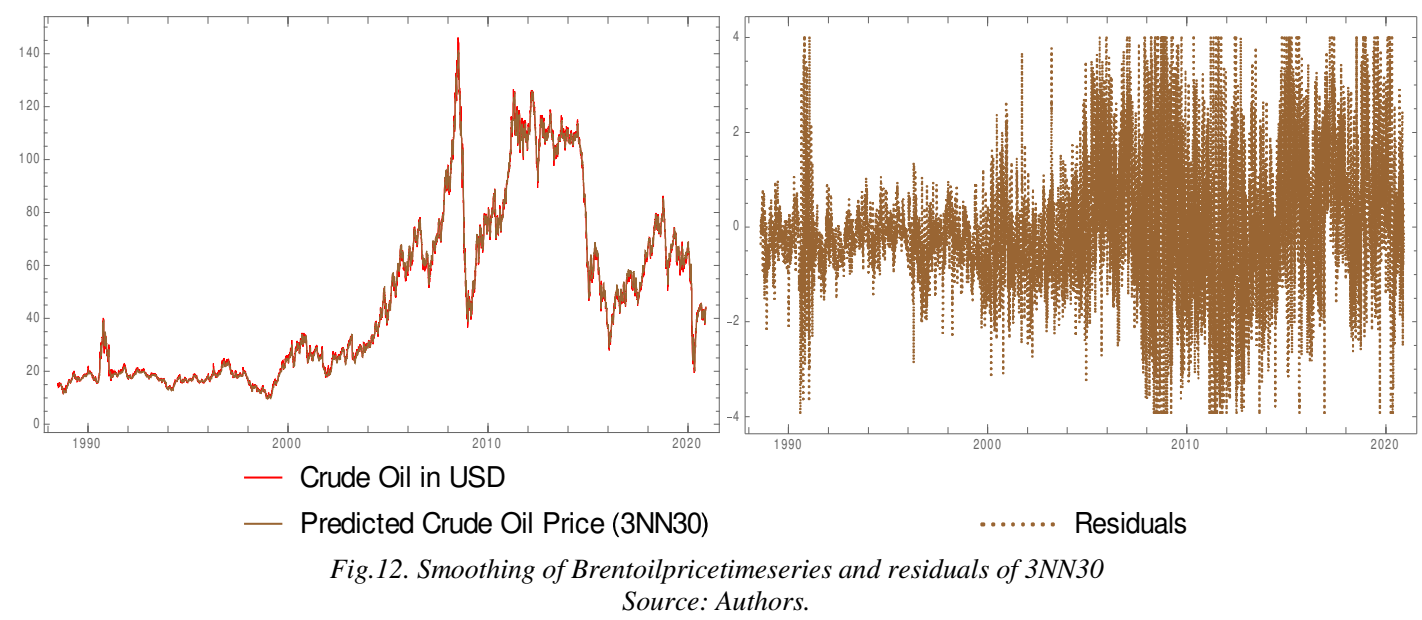

3NN30 smooths the time series under review very successfully. The prediction itself is shown in Figure 13. 


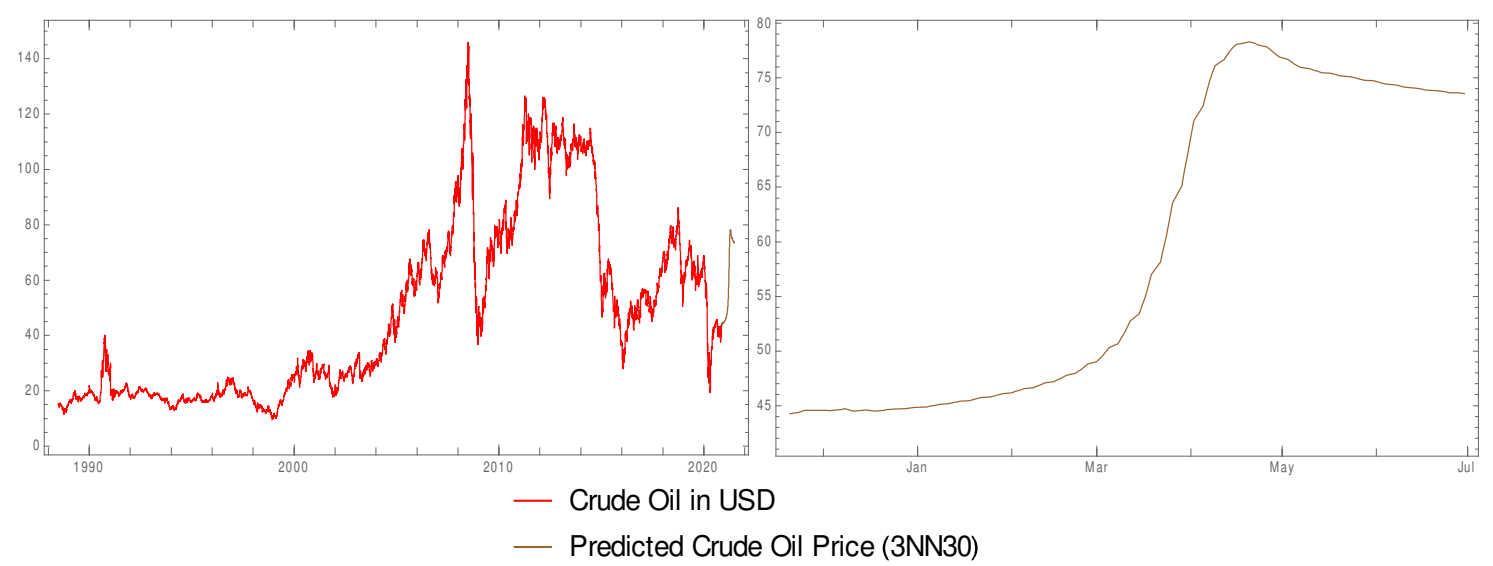

Fig.13. Prediction of Brent oil prices according to $3 N N 30$ in the context of its development to date and detail of price development in a given period

Source: Authors

In the left part, the figure shows the future development predicted by $3 \mathrm{NN} 30$ in the context of the whole monitored period, while the details are presented on the right. It could be seen that Brent oil price is stable until the beginning of March 2021. We assume that the governments of individual countries will be successful in fighting against COVID-19, and the debts will not result in a fall in the national economy's performance. After the crisis has been overcome, a sharp growth of the global economy is expected, and as a response, the oil price will change since there will be significant growth in the demand for goods and services, and the restrictions on the free movement of persons and goods will be gradually lifted. This will be reflected in the price increase to nearly USD 80 per barrel. The enthusiasm arising from overcoming the COVID-19 pandemic will subside slightly, which will result in a decrease in the oil price to USD 73-75 per barrel as of 30 June 2021.

\section{Scenario 3}

The third possible scenario assumes fast overcoming of difficult times, that is, a successful fight against COVID-19. Basically, this means the efforts to invest in production and its restructuring. There will be growth in some industries, such as tourism, food production, etc., while some industries will face a decline. However, there will be an overall significant increase in global economic performance. Such a development is predicted by 2NN10, whose diagram is presented in Figure 14.

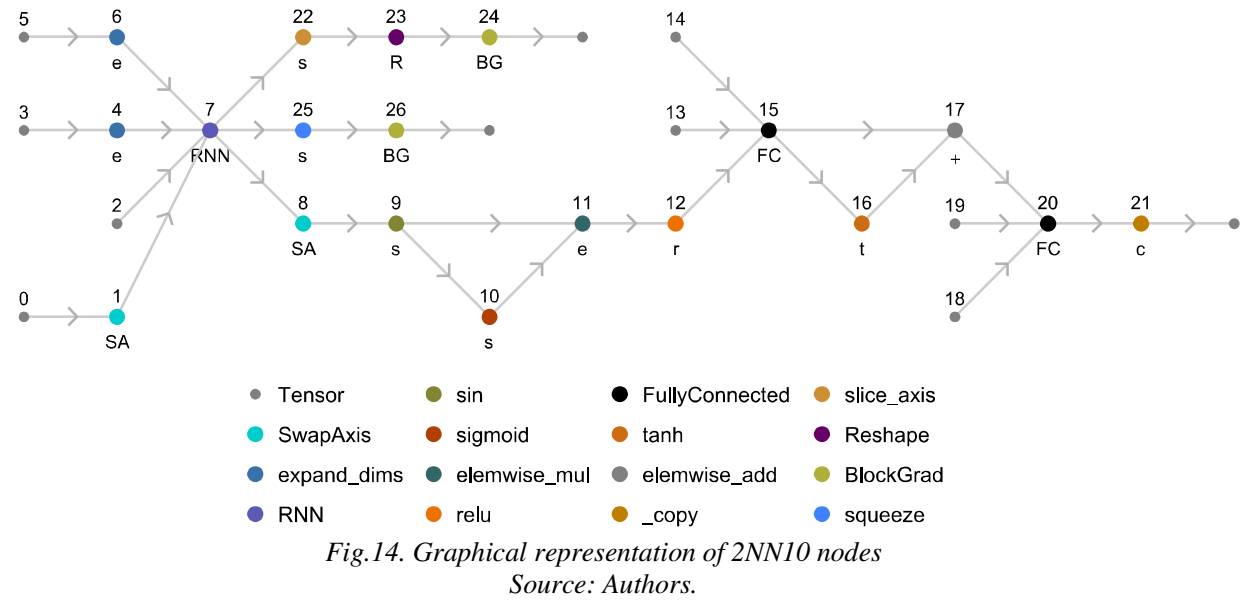

On the left side, figure 15 describes the ability of 2 NN10 to smooth the Brent oil price time series. On the right, there can be seen residuals expressed in USD per barrel. 


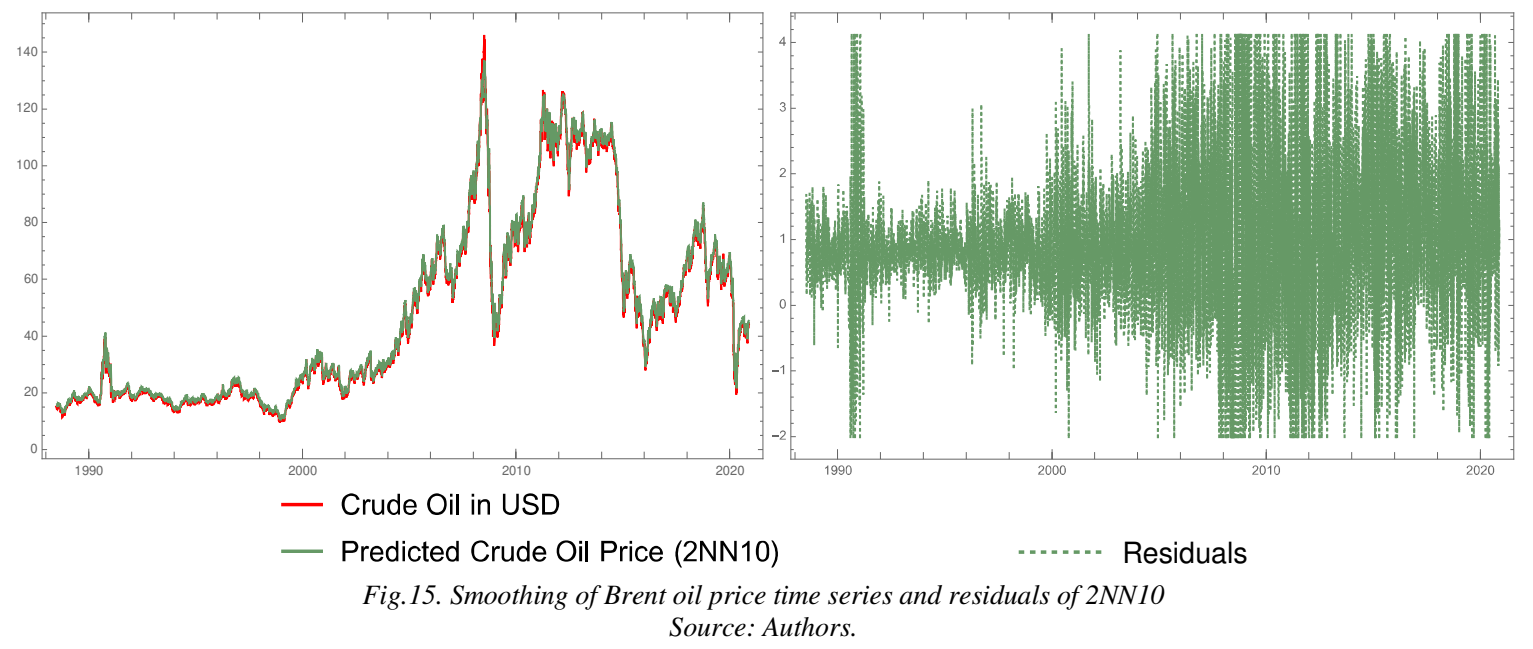

It can be seen that $2 \mathrm{NN} 10$ is also able to smooth the Brent oil price very successfully.

Figure 16 shows the prediction made by $2 \mathrm{NN} 10$ within the whole monitored period. The detail can be seen in the right part of the figure.

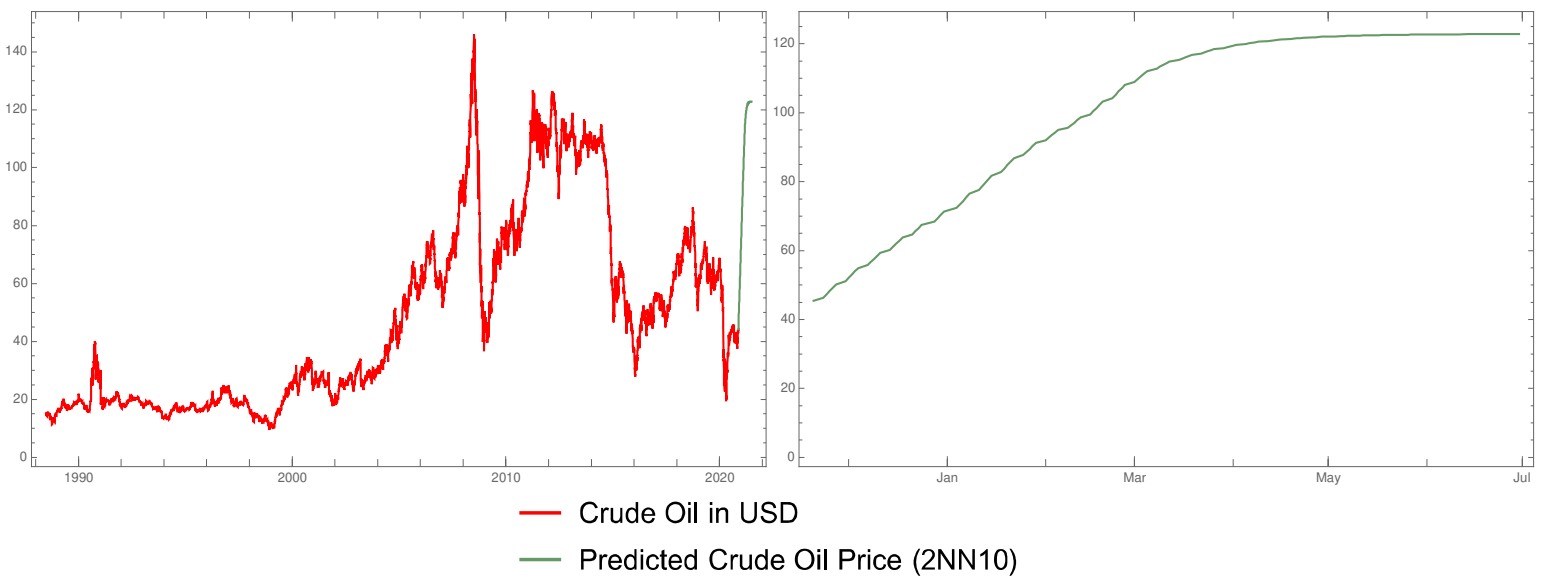

Fig.16. Prediction of Brent oil price according to $2 N N 10$ in the context of its development to date and detail of the price development in a given period Source: Authors.

The oil market will also respond to the positive development of the economy and the growth of the global economy's overall product. There will be an increase in the quantity of the extracted oil placed in the market as well as its price. According to the prediction made by $2 \mathrm{NN} 10$, there is assumed a rapid growth from the beginning of the given period and subsequent stabilization of price, probably in March 2021, at the level slightly higher than USD 120 per barrel.

\section{Discussion}

Two research questions were formulated to identify the degree of achieving the objective of the paper:

RQ1: Is a NN based on Long Short Term Memory Layer a suitable tool for smoothing the time series of Brent oil price and, thus, a suitable tool for predicting this commodity price's future development?

In the methodology part, the basic structure of NN containing the LSTM Layer was proposed. Specific networks were obtained based on the experiment's results, in which $\mathrm{NN}$ were automatically generated when changing certain parameters. The basic parameter was the number of historical prices considered in the calculation of the future price of Brent oil. The authors also worked with the change of the functions transmitting the signal within the NN. For each number of historical prices, $400 \mathrm{NN}$ were generated, which were mutually compared by their performance expressed in the form of the Pearson correlation coefficient. Out of each set, the five most successful $\mathrm{NN}$ were retained, i.e., $15 \mathrm{NN}$ in total. These were further examined. In the methodology part, it was determined that NN's performance should be above 0.95 to be applicable for predicting. All retained $\mathrm{NN}$ meet this condition; their performance is above 0.999 in all cases. Nevertheless, the truth is that the $\mathrm{NN}$ may 
suffer from overfitting. In such a case, NN shows a very good performance; however, it cannot smooth the time series and predict its future development. It was thus necessary to expertly examine all the retained NN. With regard to Figures 2, 3, 4, 5, 6, and 7, it can be stated that none of the networks suffer from overfitting. All networks are able to successfully smooth the time series under review (its global and local extremes), and their predictions are at the interval acceptable for Brent oil prices.

It can be concluded that NN with the LSTM layer are able to smooth the Brent oil price time series effectively and may be used for predicting its future development.

RQ2: What development of oil price can be expected in view of the global markets' current situation?

To answer the second research question, the future development of the global economic performance or its performance in the form of the overall product was outlined. The following three scenarios were selected:

1. The global economy will decline due to the measures adopted to fight against COVID-19.

2. The global economy will decline due to the measures adopted to fight against COVID-19, which will be followed by its growth.

3. The global economy will grow.

For all scenarios, suitable NN were selected, which predicted a possible development of Brent oil price. The first scenario was 4NN20, which predicted a gradual oil price fall to USD 32-33 per barrel as of 30 June 2021.

For the second scenario, 3NN30 was selected, predicting the stagnation of the oil price at the level of USD 45 per barrel. Its growth follows this to more than USD 80 per barrel and subsequent decrease to USD 73-75 per barrel as of 30 June 2021.

For the third scenario, 2 NN1O was used. It predicts the rise of Brent oil price to more than USD 120 per barrel and its subsequent stabilization at this level until 30 June 2021.

Interesting findings are obtained from the results of research conducted by other authors provided by other authors' results by other authors dealing with similar issues, that is, predicting Brent oil prices. For example, Abdollahi and Ebrahimi (2020) designed a hybrid model for predicting Brent oil prices. The model uses Adaptive Neuro-Fuzzy Inference System (ANFIS), Autoregressive Fractionally Integrated Moving Average ARFIMA), and Markov switching models. The results have shown that the hybrid model weighted by genetic algorithm surpasses other models. Bao et al. (2011) introduced a prognostic model for predicting Brent oil prices, which uses the least-squares SVM method and wavelet transform. On the basis of their results, they concluded that the proposed model shows high prediction accuracy. To provide an accurate prediction of Brent oil prices, Nademi, A. and Nademi, Y. (2018) used a semi-parametric Markov switching model AR-ARCH. The authors also compared this model's predictive ability with various ARIMA and GARCH models. Their research shows that semi-parametric Markov switching models provide more accurate predictions of oil prices than ARIMA and GARCH models. Morana (2001) proposed a semi-parametric GARCH model based on a bootstrap approach for predicting Brent oil prices. This model predicted oil price distribution without the need for structural specification of the conditional mean. It was also capable of calculating the confidence interval applied in predicting monthly forward price. The research conducted by Alvaraz-Diaz (2020) could also be mentioned, who dealt with the question of whether it is possible to predict Brent oil price accurately, and if yes, which method provides the best results. The author focused on predicting a weekly growth rate of Brent oil prices using several predicting methods based on various approaches. Basically, it consists of assessing and comparing the performance of linear parametric models outside ARS (ARIMA, ARFIMA, and autoregressive model), nonlinear parametric model (GARCH-in-Mean model), and various nonparametric methods based on data (nonlinear artificial NN, genetic programming, and nearest neighbor). The research results indicate that all methods are capable of providing accurate predictions of both value and trend of Brent oil price. For predicting Brent oil price, other authors thus use mainly the models based on ARIMA or GARCH. In terms of the application of a suitable method, this contribution is exceptional, as the authors used artificial intelligence - LSTM networks. These networks were found to be suitable for predicting Brent oil prices. This finding is to some extent confirmed by the research conducted by Yao and Wang (2020), who proposed a method combining the LSTM network and GM model for predicting the price of WTI oil. The results of their research indicate that the proposed model shows very high prediction accuracy. Cen and Wang (2019), who used LSTM networks within their research, state that this type of network is well suited for predicting oil prices. Finally, there can be mentioned research by Hu et al. (2019), by which the authors proved that LSTM networks are used for accurate predictions of oil prices.

\section{Conclusions}

The paper's objective was to predict the future development of daily Brent oil prices until 30 June 2021.

A total of 1,200 NN were created for a set of 10,20, and 30 input prices necessary for predicting the future development of Brent oil prices. For each set of inputs, $400 \mathrm{NN}$ were generated, out of which 5 were retained on the basis of their performance. In total, $15 \mathrm{NN}$ were retained. Each of them shows excellent parameters. The value of the Pearson correlation coefficient characterizing their performance is above 0.999 . At the same time, it 
was confirmed that each of the retained networks can successfully smooth the time series under review and can predict the future development of Brent oil price. This provides a positive answer to research question 1. Subsequently, three possible scenarios of future development of the economy were created, and three NN were selected to predict Brent oil price. This provided an answer to research question 2.

Recurrent NN work on the principle of attenuating and amplifying the signal they accept (such as, for example, perceptron networks), as well as assessing which information is undesirable for the result. For this reason, they work with the so-called forget gate. It is because the assessor often chooses a large volume of data, supposing that the larger time-series they have and smooth, the more accurate the result will be. However, this might not always be true. A smoothed time series can derive significant weights, e.g.for example, from the beginning of the time series. This provides acceptable characteristics of the time series, but the examined time series's predictions are not accurate. It is recurrent $\mathrm{NN}$, which can solve the problem of selecting a dataset (as a whole or its part), including only the necessary characteristics of the time series into the calculation. The rest of the data will be forgotten.This paper's basic finding is that the created NN with integrated LSTM is suitable for predicting Brent oil price.

Another output is the future development of oil prices with regard to the development of the economy. It follows from the text that three possible scenarios of further development can be created. It is thus clear that the measures taken by individual governments in connection with the COVID-19 will have either a positive or negative impact on the development of the world oil prices and subsequently on the development of the world economy. The presented scenarios are aimed to provide the economists with a view of the future development and explain what effect the interventions of the individual governments will have on the development of state pension and household or companies wealth. If governments took only their economic interests into account, they should not adopt any measures against COVID-19 that would have a negative impact on the development of the national economy. They should not close any establishments, restrict the economic life of a given country in any way. On the contrary, they should support companies and business activities (for example, through incentives in the form of subsidized loans, etc.). This would mean fulfilling Scenario 3. Nevertheless, it should be realized that the governments do not pursue their countries' economic interests only. They also have to consider the interests of their citizens, the voters. Basically, this means balancing and finding a compromise between the national economy's development and their electorate interests. For this reason, it is Scenario 2, which seems to be rational. Thus, the authors recommend fast implementation of major anti-epidemic measures (including a total lockdown, if necessary). This way, it will be possible to eradicate the illness within weeks. The governments should subsequently encourage households' purchasing power (by means of subsidies, contributions, soft loans) and make external resources available for companies. This will enable the growth of the economic performance. Although market participants (state, companies, households) will be indebted, they will be able to manufacture and thus pay their debts. A by-product of the world economy's growth will be a fast growth of oil prices and their subsequent stabilization at the new price level, which is about USD 73-75 per barrel. This means a price lower than in 2009 or between 2011 and 2013.

The paper's limitation can be seen in the scenarios of the future development of the global economy. It may happen that none of the scenarios will fulfill, and for some reason, the development of the global economic performance will be different, although this seems to be unlikely.

The research was conducted in the form of an experiment. Subsequently, the scenarios were created in the form of an expert opinion. It will certainly be interesting to continue with the experiment in order to find a model of a more accurate prediction of the future global economic development.It could also be interesting to examine oil price development's dependence on the economic cycles, from Kondratiev waves, through the Juglar cycle to the Kitchin cycle.

\section{References}

Aamir, M., Shabri, A. and Ishaq, M. (2018). Improving forecasting accuracy of crude oil prices using decomposition ensemble model with reconstruction of IMFs based on ARIMA model. Malaysian Journal of Fundamental and Applied Sciences, 14(4), 471-483.

Abdollahi, H. and Ebrahimi S. B. (2020). A new hybrid model for forecasting Brent crude oil price. Energy, 200.

Ahmadi, M., Bashiri, N. and Manera, M. (2016). How is volatility in commodity markets linked to oil price shocks? Energy Economics, 59, 11-23.

Alvarez-Diaz, M. (2020). Is it possible to accurately forecast the evolution of Brent crude oil prices? An answer based on parametric and nonparametric forecasting methods. Empirical Economics, 59(3), 1285-1305.

Bao, Y., Zhang, X., Yu, L., Lai, K. and Wang, S. (2011). An integrated model using wavelet decomposition and least squares support vector machines for monthly crude oil prices forecasting. New Mathematics and Natural Computation, 7(2), 299-311 
Baumeister, C. and Kilian, L. (2015). Forecasting the real price of oil in a changing world - a forecast combination approach. Journal of Business and Economic Statistics, 33(3), 338-351.

Cen, Z.P. and Wang, J. (2019). Crude oil price prediction model with long short term memory deep learning based on prior knowledge data transfer. Energy, 169, 160-171.

Chai, J., Wang,Y. Wang, S. and Wang, Y. (2019). A decomposition - integration model with dynamic fuzzy reconstruction for crude oil price prediction and the implications for sustainable development. Journal of Cleaner Production, 229, 775-786. ISSN 09596526.

Chiroma, H., Abdulkareem, S. and Herawan, T. (2015). Evolutionary neural network model for West Texas intermediate crude oil price prediction. Applied Energy, 142, 266-273.

Gao, S. and Lei, Y. (2017). A new approach for crude oil price prediction based on stream learning. Geoscience Frontiers, 8(1), 183-187.

Hu, H.Q., Wei, W. and Chang, C.P. (2019). Do shale gas and oil productions move in convergence? An investigation using unit root tests with structural breaks. Economic Modelling, 77, 21-33.

Investing.com. (2020). Brent Oil Futures - Feb 21 (BG1). [online]. [cit. 2020-11-27]. Available from: https://www.investing.com/commodities/brent-oil-historical-data.

Kilian, L. (2009). Not all oil price shocks are alike: disentangling demand and supply shocks in the crude oil market. American Economic Review, 99(3), 1053-1069.

Kilian, L. and Lee, T. K. (2014). Quantifying the speculative component in the real price of oil: The role of global oil inventories. Journal of International Money Finance, 42(2), 71-87.

Kingma, D. P. and Ba, J. L. (2015). Adam: A method for stochastic optimization. 3rd International Conference on Learning Representations, ICLR 2015 - Conference Track Proceedings2015.

Klieštik, T., Vrbka, J. and Rowland, Z. (2018). Bankruptcy prediction in Visegrad group countries using multiple discriminant analysis. Equilibrium-Quarterly Journal of Economics and Economic Policy, 13(3), 569-593.

Lin, Y., Xiao, Y. and Li, F.X. (2020). Forecasting crude oil price volatility via a HM-EGARCH model. Energy Economics, 87, 104693.

Machová, V., Krulický T. and Horák, J. (2020). Comparison of neural networks and regression time series in estimating the development of the afternoon price of gold on the New York stock exchange. Social and Economic Revue, 1, 61-72.

Morana, C. (2001). A semiparametric approach to short-term oil price forecasting. Energy Economics, 23(3), 325-338.

Nademi, A. and Nademi, Y. (2018). Forecasting crude oil prices by a semiparametric Markov switching model: OPEC, WTI, and Brent cases. Energy Economics, 74, 757-766.

Novotný, F. (2012). The link between the Brent crude oil price and the US Dollar exchange rate. Prague Economic Papers, 21(2), 220-232.

Qi, Y. L. and Zhang, W. (2009). The improved SVM method for forecasting the fluctuation of international crude oil price. International Conference on Electronic Commerce and Business Intelligence, 269-271.

Qiang, W., Lin, A., Zhao, C., Liu, Z.,Liu, M. and Wang, X. (2019). The impact of international crude oil price fluctuation on the exchange rate of petroleum-importing countries: a summary of recent studies. Natural Hazards, 95(1-2), 227-239.

Ramyar, S. and Kianfar, F. (2019). Forecasting crude oil prices: A comparison between artificial neural networks and vector autoregressive models. Computational Economics, 53(2), 743-761.

Rehman, M. U., Shahzad, S. J. H., Uddin, G. S. and Hedstrom, A. (2018). Precious metal returns and oil shocks: A time varying connectedness approach. Resources Policy, 58, 77-89

Tairan, N., Shah, H. and Aleryani, A. (2019). Prediction of crude oil prices using hybrid guided Best-So-Far honey bees algorithm-neural networks. International Journal of Advanced Computer Science and Applications, 10(5), 317-330.

Tang, L., Dai, W. and Yu, L. (2015). A novel CEEMD-based EELM ensemble learning paradigm for crude oil price forecasting. International Journal of Information Technology \& Decision Making, 14(01),141-169

Vochozka, M., Rowland, Z., Šuleř, P. and Maroušek, J. (2020). The influence of the international price of oil on the value of the EUR/USD exchange rate. Journal of Competitiveness, 12(2), 167-190.

Wang, S. P., Hu, A. M. and Wu, Z. X. (2015). Time series long-term forecasting model based on information granules and fuzzy clustering.Engineering Applications of Artificial Intelligence, 41,17-24.

Wang, J. Q., Du, Y. and Wang, J. (2020). LSTM based long-term energy consumption prediction with periodicity. Energy, 197.

Wang, Y.D., Wu, C.F. and Wei, Y. (2011). Can GARCH-class models capture long memory in WTI crude oil markets? Economic Modelling, 28, 921-927.

Wang., J., Niu, T., Du, P. and Yang, W. (2020). Ensemble probabilistic prediction approach for modeling uncertainty in crude oil price. Applied Soft Computing, 95. 
Yao, T. and Wang, Z. (2020). Crude oil price prediction based on LSTM network and GM $(1,1)$ model. Grey Systems-Theory and Application, ahead-of-print. 